\title{
Talent Management for High-Quality Employee: Example of China
}

\author{
Dan Zhou
}

\begin{abstract}
Talent is core competitiveness to the business and nation; the quantity and quality of talent pool will influence the whole nation's development. Consequently, management practices will make a difference in attracting talent, moreover, each national context have its own way to attract talent. This paper focus on the high-quality talent which is corresponding to the national talent program in China. Firstly, define the concept of talent management and high-quality talent management. Secondly, explicitly explain problems of what is high-quality talent, why to highlight this type of talent, how to recruit these talents. Thirdly, research development in high-quality talent management. Finally, limitation and future research.
\end{abstract}

Index Terms - China, core competitiveness, high-quality talent, talent management.

\section{INTRODUCTION}

Talent management has been a topic of central interest to practitioners and academics, especially in the globalization context. Essentially, talent management is related to creating a talent pool from external and internal sources, adequately deploying these resources in pivotal positions, and further, work on their work motivation, organizational commitment and extra roles behaviors that contribute to organizational performance [1]. Governments and various organizations attach great importance to the work of human resources, and treat talent as a significant driving force for social economic development. Talents are regarded as an elite subset of the organization's population-i.e. "(...) those individuals who can make a difference to organizational performance, either through their immediate contribution or in the longer-term by demonstrating the highest levels of potential" [2].

There are some arguments about the importance of talent management and exists many criticisms about the way it is applied in practice. Proper talent management is considered a critical determinant of organizational success , and imperative for the livelihood and sustainability of organizations [3]. But to what extent can talent management contribute to the social development and growth of society, creating conditions for its citizens to live a fulfilled life [4]? Although studies of talent management in small and medium-sized enterprises and public organizations have been slow to appear, there are a growing number articles on talent management in different

Manuscript received March 5, 2017; revised June 3, 2017. This work was supported in part by the Chinese Scholarship Council and Zhongnan University of Economics and Law postgraduate innovation education program under Grant 2015BZ1202.

Dan Zhou is with the Public Administration School, Zhongnan University of Economics and Law, 430000, China; She is also with School of Business and Management, Queen Mary, University of London, E1 4NS, UK (e-mail: zhoudan65@ outlook.com). geographies, not least in China [5], [7]. Other gaps are also being filled, such as talent management in different sectors [8] and the different roles for enactment of talent management [9].

As there is no consistent definition of either talent or talent management in the academic literature [10], therefore, all definitions are context-driven and cannot be universal [4]. Thus, this paper will define the concept of talent and talent management in the context of China. Especially on Chinese labor market's specific talent, who are mainly assembled in the Chinese public sector organizations. In China, those talents have a unique classification- (Gao Ceng ci) High-quality talents. Subsequently, this article will focus on the talent management for high-quality talents in Chinese labor market from a macro perspective.

\section{TALENT MANAGEMENT LiteratuRE REVIEW}

Although there is no consensus or consistent definition of talent management; it is interpreted in various ways [11], [13]. However, as stated by the reference [14], there is "a disturbing lack of clarity regarding the definition, scope and overall goals of talent management." In this regard, Lewis and Heckman identify three key streams of thinking regarding what talent management is.

The first stream appears to be merely substituting the label talent management for human resource management, often limiting their focus to particular HR practices such as recruitment, leadership development, succession planning and the like.

A second stream emphasizes the development of talent pools focusing on "projecting employee/staffing needs and managing the progression of employees through positions", [14] typically building upon earlier research in the manpower planning or succession planning literatures.

The third stream focuses on the management of talented people. This literature argues that all roles within the organization should be filled with "A performers", referred to as "top grading" [15] and emphasizes the management of "C players", or consistently poor performers, out of the organization [16]. Reference [1] identify a further stream. This stream emphasizes the identification of key positions which have the potential to differentially impact the competitive advantage of the firm [17], [18].

Our research is in close proximity to the last trends, nevertheless, some difference exists. The "A performers" could be any types of talent in the organization's talent pool, while, our research will narrow the scope into the limited amount of talent, who are in the highest layer of the talent hierarchy. Those high-quality talents normally occupy the key positions in the organization and are presented as the "top 
grading player" who have the important impact on the competitiveness of the organization.

Moreover, talent management has been defined in broad terms as an organization's efforts to attract, select, develop, and retain key talented employees on a global scale [19]. A key aspect of this definition is the focus on a key group of core employees, rather than the multinational's entire human capital pool [17], [20]. These viewpoints emphasize organizations' strategic priorities in utilizing the core employee to fulfil the organization's goal. Meanwhile, a certain group of studies noted that different national contexts will result in different approaches for talent management. As such, reference [21] explore talent management in the Indian context; reference [7] contribution considers the Chinese context. Thereinto, reference [21] argue that even with the global economic slowdown of 2008 and 2009, there are continuing challenges in attracting, managing, and retaining talent, especially in the developing regions of the world where economic activity has outpaced the availability of skilled employees. By researching seven multinational corporations (MNCs) in Beijing, reference [12] found an 'exclusive-people' focus on certain groups of 'high-performing' or 'high-potential' people, whilst for others it meant an 'exclusive-position' focus on certain 'key' positions in the organization. The division of "exclusive-people" is based on segmentation of the workforce in the organizations, and categories ' $\mathrm{A}$ ' is those top 10 20\% [22].

To be more specific, China government officially enforced the National Talent Strategy and Policy, which is especially design for specific group of talents. Most scholars have note this new contextual Talent problem in China. This specific group of talents are characterized as high-quality employee, who is directly related to enhancing the national core competitiveness, achieving the strategic objective of building an innovative country, promoting technological progress and development of enterprises. Or we can entitle it as "highly qualified human capital(professional)", which is referred to the Chinese human capital who continues to work abroad and periodically return home, for example, as a Visiting Professor, so that the employer(organizations) establish a circuit of technological and scientific diffusion which is necessary for the development of its economic system [23]. This kind of Talent is close to the notion 'high-quality immigration (HSI)' who are defined here as those with a university degree, working in occupations in relevant sectors (such as engineering, medical sciences, information communications and technology) and/or earning high incomes [24].

Generally speaking, contextual factors arouse the debate on the consistent definition of talent management, and expand the breadth and depth of research. Thereinto, inspired by reference [13], talent management for high-quality employee in China refers to all organizational activities for attracting, selecting, developing, and retaining the top-rated performance employees in the most core roles.

\section{EXPLICITLY ANALYSIS OF HIGH-QUALITY TALENT}

\section{A. What Is High-Quality Talent in the Chinese Context}

High-quality talents ( $\mathrm{Gao} \mathrm{Ceng} \mathrm{Ci}$ ) is a specific description in Chinese context. Currently, there is no definitive definition about high-quality talent in academic research books. Although there have been many references to the Talent Policy document, there is no conceptual definition.

The concept of high-quality talent is put forward firstly at China Communist party's congress report Part XII, in 2007. The guideline of the report is " respect for labor, respect for talent, respect for the creation"; in addition, the principle is "human resources under the Party leadership", treat high quality professionals and highly skilled workers as the focus of all kinds of personnel construction. "

In 2007, the, "By the spirit of reform and innovation to comprehensively promote the party building the new great project", put forward the guidelines that; insist on the Building an innovative personnel work system and mechanism to stimulate all kinds of talent to create vitality and entrepreneurial enthusiasm, in addition create new situation, that talent resources are profuse and talents should be in right place."

After the 17th National Congress, China has gradually strengthened the introduction of overseas high-quality personnel, especially after August 2008, when the financial crisis began to sweep the United States, the European Union and Japan and other major financial markets in the world. In response to the financial crisis, China initiated "the Recruitment Program of Global Experts" (known as "the Thousand Talents Plan") at the end of 2008, to bring in overseas top talents to China over the next five to ten years. Relying upon National Key Innovation Projects, National Key Disciplines, and National Key Laboratories, central SOEs and state-owned commercial and financial institutions, and various industrial parks (mainly the high-tech development zones), this plan called for strategic scientists or leading talents who can make breakthroughs in key technologies or can enhance China's high-tech industries and emerging disciplines. Furthermore, in accordance with the spirit of the central authorities' document, each province government in China has also developed respective introduction plan (www.1000plan.org/qrjh/article/61537 n.d.)

Another authoritative policy document is National Program for Medium and Long - Term Talent Development (2010-2020). This document puts forward the guideline of talent development in China: "service development, talents first, use - oriented, innovation mechanism, high - end lead and overall development (2010 National program,). There are eight types of talents mentioned in this program, including leadership talents; entrepreneurs; scientists; experts, writers, artists, educators; high-quality personnel; new rural construction leaders; professional senior social worker; economic and social development leader.

We can conclude from above documents that high-quality talent is defined as professionals in all sectors of the industry that have a high level of knowledge, strong professional capacity, and innovation, along with greatest contribution.

In summary, high-quality talent is a unique title exist in Chinese' talent market, and affected by some bureaucratic factors. We can define these high-quality talents as follows: High-quality talents refer to some professionals group with distinguished knowledge level, strong innovation ability and 
brilliant social contribution in various fields. Additionally, those talents' scientific research field normally primarily assembled in public sector organizations, such as colleges, universities, state-owned enterprises, and commercial financial institutions and so on. Although different organizations have initiated their respective criteria for the talents introduction, but authorized professionals are more or less consistently including: Member(s) of Chinese Academy of Engineering ; Member(s) of Chinese Academy of Sciences; specialists in major projects for talent development; national and provincial academic pacesetter; overseas returnee; personnel with doctorate or master's degrees, personnel with qualifications of senior professional and technical positions, and professionals in short supply etc. In other words, those terms can be concluded as three points: high education, high academic accomplishment, high occupation status.

\section{B. Why to highlight the High-Quality Talents}

\section{1) Global talent competitiveness}

Either for the business or for state economies, talent especially the high-skilled talent has become the core currency of competitiveness. With the purpose of indicate the correlation between economic performance and combination of occupational skill locally, GTCI (Global Talent Competitiveness Index) confirm this positive correlation. Across all income groups and levels of development, countries that focus methodically more on talent competitiveness inclined to do better. Just as this GTCI report indicate, there is no 'one -size-fit-all' approach to talent strategies, and each national context required its own ways of attaining the right mix and levels of vocational and global knowledge skills. Consequently, in China, the own way of upgrading and increasing the quantity and quality of talent is the implementation of high-quality talent program.

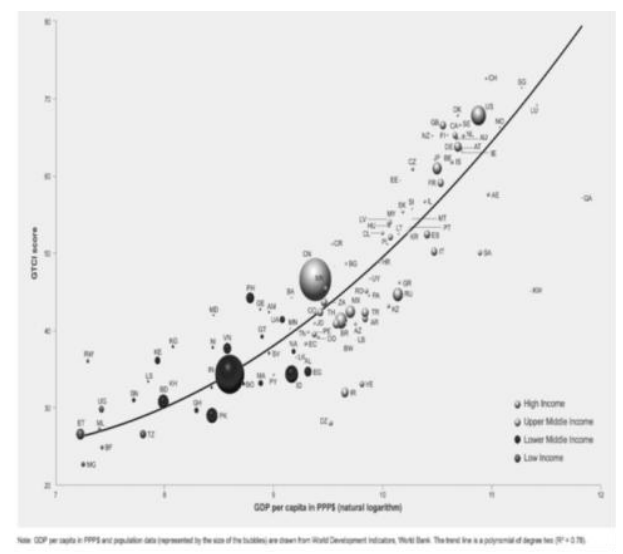

Fig 1. Global talent competitive index 2015-16. Source: GTCI Brochure 2015-16

Fig. 1 indicates that China is a developing state, and a upper middle income country, GDP per capita is US\$13,206(CHN human capital report 2016). Although China's GDP ranked 2nd in the worldwide, but the GTCI lies in the lower middle level. Take the 25-54 age group for example, as the main constituent of labor force, it's skills structure is not competitive. Table I shows the current human capital skills structure, thereinto, high-skilled employee only rank 96th in the world, far less behind the mean value. Also the medium-skilled employee is only in the medium level. As the core currency of competitiveness, high-quality talent's share influence the stable development of the whole business and nation.

TABLE I: China Human CAPITAL SKILls STRUCTURE Source: Human Capital Report 2016

\begin{tabular}{llll}
\hline \hline Skills & Value & Score & Rank \\
\hline High-skilled employment share & 12.10 & 12.10 & 96 \\
$\begin{array}{l}\text { Medium-skilled employment } \\
\text { share }\end{array}$ & 91.60 & 91.60 & 36 \\
Ease of finding skilled employees & 4.43 & 57.22 & 39 \\
\hline \hline
\end{tabular}

Furthermore, according to the Human Capital Report 2016, China (71) similarly ranks in the mid-range of the overall Index scores, well ahead of the other BRICS nations except for the Russian Federation. Its younger population fares significantly better than its 55-64 and 65 and over age groups as a result of increasing educational attainment in the population. Fig. 2 shows the high Graduate degree occupied rate in the 25-54 age group.

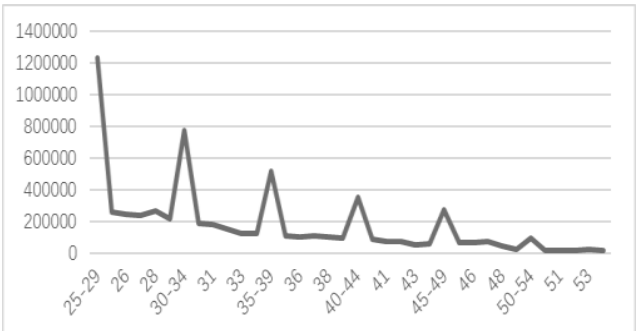

Fig. 2. Graduate degree occupied rate in different age group(2010). Source: national bureau of statistics of China(2010)

It also scores comparatively well on the Ease of finding skilled employees (39th), Vocational enrolment (29th) and Economic complexity (18th) indicators, setting the country up well for the future (Human Capital Report 2016).

2) Increasing the attractiveness for talent

Chinese government have implemented China 's Talent Strategy Policy for a few years, more students and scholars go abroad to learn advanced sciences and techniques in short or long terms. Returnees, particularly those in the private sector, engage in technology transfer, importing high-level technology unavailable in China. From the statistics of China Ministry of Education Service Center, in line with the statistics of year 2015 and 2014, China's number of study abroad and the returned overseas students have further increased. The number of students studying abroad increased by 6.39 million, an increase of $13.9 \%$; the number of returned overseas students increased by 44,300 , an increase of $12.1 \%$. Fig. 3 shows the change of students going abroad / returning to China from 1978-2014. Based on the abundant accomplishment of China's "Reform and Opening up" policy, both these two amounts increased quickly since 2002. Fig.4 indicate the proportion of the number of people going abroad / returning to China decreased quickly since 2002, which is from 6.98 to 1.26 . Fig. 5 shows the percentage of the diploma of the returnee student, master and doctor degree account for the huge proportions, which also contribute to the mostly of the returnee. Comparing from these three figures, we can conclude that although the returnee increasing year by year, 
but the sheer number of expatriate still higher than returnee. Subsequently, China government deepen the implementation of high-quality talent recruitment program.

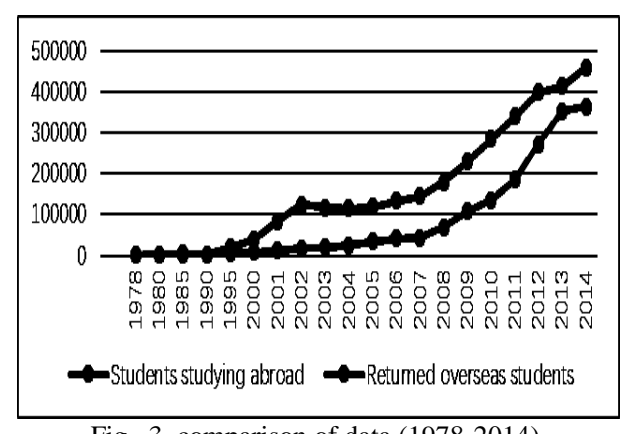

Fig. 3. comparison of data (1978-2014). Source: National Bureau of Statistics of China 2015

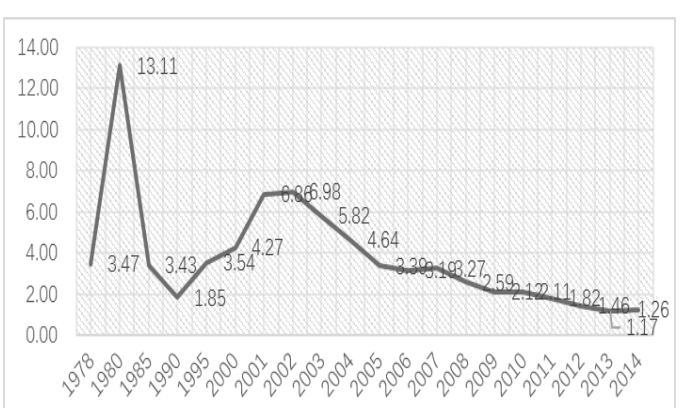

Fig. 4. The proportion of student going abroad / returning to China (1978-2014).

Source: The Blue Book of Returning to China2015

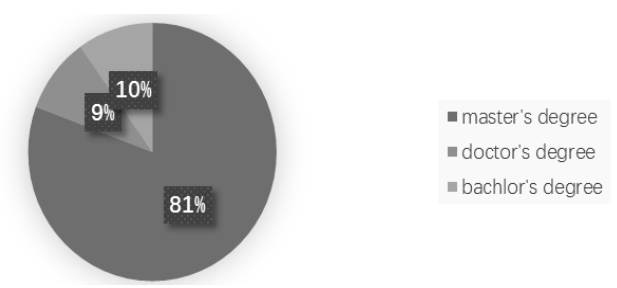

Fig. 5. The Educational Composition of Returnee (2015) Source: The Blue Book of Returning to China 2015.

\section{How to Implement High-Quality Talents Management}

\section{1) The recruitment program of global experts}

This program is a landmark policy for the construction of high-quality talent team. In this program, recruitment target is mainly divided into three parts.

a) Recruitment program for young professionals

This program aimed at overseas young scholars. Their teaching and researching experiences in overseas institutions and universities are the vital antecedents for Chinese scientific organizations, especially the public-sector organizations. Once those talents got the post in Chinese organizations, they will get the initial of US\$73,000 per person, and research subsidies from US\$145,000 to US $\$ 434,000$ consistent with the level and quality of the program. These excellent pay and conditions are competitive with the post in developed countries.

\section{b) The Recruitment program for entrepreneurs}

This program aimed at the Entrepreneurial talents who have overseas education and working experience. By recruitment of these types of talents, the organization can benefit from their technologies or invention patents which lies in the leading position by international standard. Awardees will be conferred the title of "the National Distinguished Expert" and be provided with enabling working and living conditions.

\section{c) The recruitment program for foreign experts}

This program aimed at foreign nationality experts. Besides the preferential policies in terms of exit and entrance, residence, medical care, insurance, housing, tax, salary, etc., these talents would be granted total amount of US\$434,000-723,000million research subsidies. Nevertheless, these talents must commit to work for more than 9 months per year in China for 3 consecutive years. In 2015, China expand the favorable visa policies of its Thousand Talents Plan to 55 programs nationwide to attract leading professionals to work in the country. And since the implementation of the program, the introduction of high-quality talent more than 4100 persons (China daily). In addition to the "Thousand Talents Plan", the state encourages and supports all levels of overseas high-quality personnel to return to work (in China). Those who do not meet the "Thousand Talent Plan" conditions, but wish to return to China (work in China), can apply for the Ministry of Education "Cheung Kong Scholars Program"; The "Hundred Talents Program" of the Chinese Academy of Sciences; The National Science Fund for Distinguished Young Scholars of the National Natural Science Foundation, and the talent introduction projects in other bureau departments and provinces, districts and cities.

\section{2) Special support program for national high-quality professionals}

Official Recruitment for overseas high-quality personnel is on one side, fostering and supporting national talents is on the other side, with both side working hard all the time. On September 2012, "Special Support Program for National High-quality professionals" (known as "Ten Thousand Talents Program" was officially launched. This plan is ready to use 10 years or so, the selection to support 10,000 high-quality professionals. These professionals are classified into 3 layers, which include 7 types of personnel: the first layer include 100 personnel, named as Eminent scientist(s); the second layer include 8000personnel, named as Leading scientist(s), such as scientific innovation leading scientist, technology entrepreneur leading scientist, philosophy social sciences leading scientist, outstanding teacher, Millions of Leading Engineering Talents; the third layer include 2000personnel, named as Young top-notch talent.

Both the Thousand Talent Program and Ten Thousand Talent Program are main parts of high-quality Talent recruitment program, and each organization have their respective employment criteria along with the guideline of National talent program. Currently, research about assessing the effect of overseas talent introduction policy is still in the initial stage. Based on the analysis of the status quo of the high-level talents introduction in Changzhou, reference [25] designs the evaluation index system of overseas high-level talent introduction policy, from the dimensions of "attracting, retaining, using well". Reference [26] analyze the returnee's talent satisfaction level. Reference [27] construct an evaluation index system of overseas high - level talent 
introduction policy effect, from the perspective of input to output. Since this talent program implemented in China no more than ten years, the relevant empirical research is less.

If classified by the geographical source, high-quality talent come from both overseas and domestic labor market. Fig. 1 is the constitute of current high-quality talent in China.

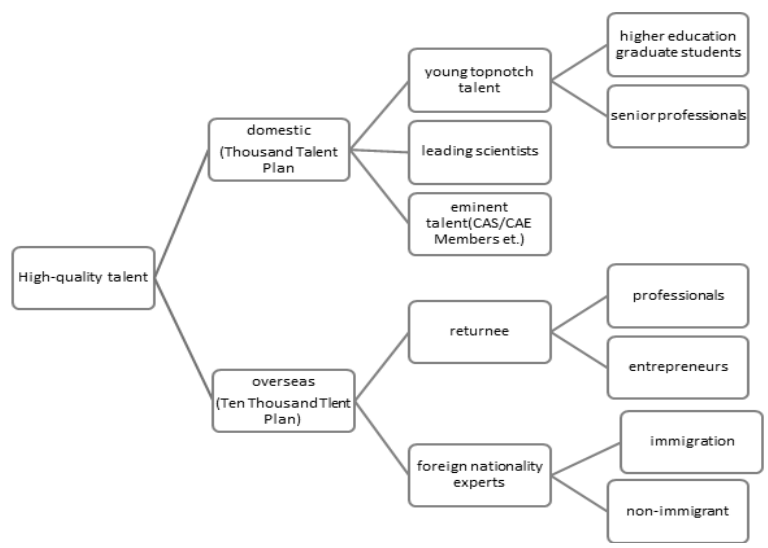

Fig. 6. Map of high-quality talent.

Basically, abstracting from the various talent policies and programs in China governments and organizations at all level, this paper compile the map of high-quality talent in Chinese organizations. Domestic and overseas talents are the main resources of Chinese high-quality talent. Most of the high-quality talent comes from overseas, some are returnee who graduate from oversea universities and some are foreign nationality experts. China's local higher education organizations training a lot of talents, thereinto, young top-notch talents, leading scientists and eminent talents are main constituent.

In the process of the implement and development of high-quality Talent program, excluding those entrepreneurs who establish their own business, most of high-quality talents are recruited into the public-sector organizations which got the financial support from Chinese government. Thereby, a series of problems exposed which are caused by high-quality talent management, such as incomplete talent selection and evaluation system [28], top rated talents is still scarcer, most of the science and engineering talents who are in most demand didn't return [29].

\section{3) The silk road economic belt and the 21st-century maritime silk road policy}

China has tasted the bitter consequences of the policy of "closed-door" policy in the long process of social development, and because of this, China is also a firmly promoter of globalization. The Silk Road Economic Belt and the 21st Century Maritime Silk Road policy which issued on September, 2013 by China are national top-rated strategy, has brought an opportunity to attract more talent around the world. The initiative to jointly build the Belt and Road, embracing the trend towards a multipolar world, economic globalization, cultural diversity, and greater IT application, is designed to uphold the global free trade regime and the open world economy in the spirit of open regional cooperation. It is aimed at promoting orderly and free flow of economic factors, highly efficient allocation of resources and deep integration of markets; encouraging the countries along the Belt and Road to achieve economic policy coordination and carry out broader and more in-depth regional cooperation of higher standards; and jointly creating an open, inclusive, and balanced regional economic cooperation architecture that benefits all. One of the cooperation priorities is to increase personnel exchange and cooperation between countries along the Belt and Road, such as extensive cultural and academic exchanges, personnel exchanges and cooperation, media cooperation, youth and women exchanges and volunteer services. This policy will enhance the priority and preference of National fund support and increase the possibility for successfully high-quality talents recruitment.

\section{4) Conclusion}

Contextually-based research is important in Talent Management process, and contribute to the building of a broader and more balanced theoretical framework for Talent Management, both organizational context and its interrelated actors would impact the implement of Talent Management (Thunnissen, 2016). High-quality talents are significant constitution in the construction of the China Strategy of reinvigorating through science, education, and human resource. The key point of this National high-quality talent recruitment program is to accelerate overseas talent backflows along with the updated science and technology introduction. While well intentioned, but outcome is not fully expected. Some local governments and relevant administrative bureaucratic sectors treat these talents programs as vanity projects because there is obvious competitive relationship around them [27]. For example, Shanghai is the earlier city to introduce intelligence projects, and the implementation effect is outstanding. However, with the increase of overseas returnee flow, the knowledge spillover effect gradually appeared, many cities copied Shanghai's experience and carried out similar policies without much differences. The outcome state that the amount of funds and preferential policies are not the only factors that attract high-quality talents, the post and job contents are also the imperative factors.

Inevitably, Chinese high-quality talent recruitment program would be compared with some developed countries' relevant program, e.g. British Highly Skilled Immigration Program between 2002- 2008 and the French Carte de Competences et Talents (Card of Competences and Talents) from 2006 to 2009. But how to evaluate the effect of Chinese high-quality talent program, and what's the competitive advantage of Chinese talent recruitment program in worldwide talent war? Based on the political, economic context differences in China, Chinese characteristic high-quality talent program is in highly demand which worth both researchers and organizational behaviors to practice.

\section{THEORETICAL RESEARCH DEVELOPMENT ON High-QUALITY TALENT MANAGEMENT IN CHINA}

Currently, most of the literatures about Chinese high-quality talent management are mainly from the macro perspective, such as the management mechanism and model [30], talent induction [31], [32]. Organizations' role in talent management from micro perspective are less attention. Following parts would focus on research about organizations. 
The first part is about the talent flow features in Chinese organizations. The second part is about the organizations' work both before-induction and after-induction.

\section{A. Features of Talent Flow in Chinese Organizations}

Organizations with stable, established career paths may be better prepared to attract and retain scarce talent than other organizations[33]. For some highly qualified groups in the labor market, this impact leads to increased bargaining power, because companies have a greater need to update knowledge and may need knowledge workers more than knowledge workers need companies [34]. Whilst organizations will externally recruit for some positions at high levels, creating a pipeline of internal talent remains a central pillar of succession planning for the senior management team in global companies, with an average ratio of 70/30 internal to external talent acquisition [35].

Along with a series broadly and substantially national and local administrative level Talent Program implemented continuously, many outstanding overseas personnel flow into Chinese organizations. In 2016, the 12th batch of "Thousand Talents Program" were completed, 866 experts were recruited. The 13th batch of selection work were completed, which is expected to introduce more than 960 experts. Meanwhile, the 2nd batch of national "million people plan" selection work were completed, recruited 1702 domestic experts, including 2521 expert candidates [36].

Relevant problems emerged one after another. On the one hand, these favorable conditions attract more westerners and expatriate talents. They treat China as the most challenging expatriation location [37] to comprehend and work in efficiently [38]. Challenges may stem for example from typical Chinese organizational behavior, which is based on the concept of long-term group membership (guanxi)[39]. From this perspective, foreigners in general are usually treated as members of an out-group. Accordingly, they are likely to receive less social or professional support from local co-workers or superiors than would be offered to locals [40].

One of the representative case is the "Professor Mao Changxuan event" happened in Shanghai University of Finance and Economics. This 43-year-old professor Mao Changxuan was a young professor recruited in 2010 by the Shanghai University of Finance and Economics from the United States. But he who would have "permanent position (like the North American Tenure System in Universities)" status, he was told that the school, after six years of employment expires, will not renew his professor contract. In accordance with the newspaper report, cultural contradiction between this professor and some relevant leaders are the main reason (The China Press).

The Chinese language also creates issues for foreigners [41]. Such challenges have been cited as reasons for expatriates leaving a host country. The notion suggests that expatriate workers in China require some different strategies for managing their careers than those used by expatriates working in the West. In fact, those working for local organizations in China or in any other culturally distant career context should have a well-developed cultural understanding and strong communicative abilities [42]. Moreover, self-efficacy, marital status, and family attachment are vital antecedents, covariates, and consequences of attractiveness to expatriate workers [43], [44].

On the other hand, Chinese organizations issued preferential policies to promote talents who have overseas education and working experience, especially so called high-quality talents. Articles in the press and on websites in China refer to this confrontation, criticizing the decision of organizations to favors "outsiders" who have studied abroad over long-term staff members who have not been overseas (cited from http://www.wenxuecity.com).

For the Chinese organizations, this discrepancy also appears in the dispute between local talent and introduced overseas professionals. Returnees are of a higher academic caliber than people who have not gone abroad. All surveys of universities, research laboratories and science parks show that returnees possess skills, information and research methodologies that are generally unavailable to people who have not gone abroad [45]. The Local talent thought the government "overemphasized outsiders", and those introduced overseas talent thereby got preferential treatment. But the performance of those introduced high-quality talent is not satisfactory, the problem of counterfeiting and fraud are often seen on the newspaper. Scholars found that this phenomenon may be caused by lack of liberal scientific research environment, non-flexible scientific research management system, and internal crowding phenomenon [46].

\section{B. Theoretical Analysis}

As the High-quality talent programs are implemented since 2008 , so the relevant researches are mostly developed no more than ten years. Along with the search on the current literatures, the research can be divided into following parts: i. regional discrepancy, e.g. analysis of High-quality talent policy enforcement in Tianjin, Fujian, Anhui, Guangdong, Hubei provinces and municipalities etc. [47], [48]; ii. single perspective, many papers carry out the research from a single level, such as from high-education universities, state-fund firms, hospitals and research institutes [49], [50]; iii. micro perspective, such as high-quality talent introduces, compensation, evaluation and relevant policy comparative. [32] and [51].

From the integral perspective, China's high-quality personnel policy is characterized by "weak law", "incentive officialization", "project fragmentation", "weak commercialization", "value introducing but neglect self-cultivation", [52], [53]. The weak law refers to the phenomenon that in the system of China's high-quality personnel, the proportion of government regulations is too large but laws and regulations significantly weakened, which is not conducive to the continuity of personnel policy. Incentive officialization means Chinese organizations often emphasizes and highlights the incentive function of executive positions in the policy of talent incentive, and cannot really form the humanistic environment and scientific atmosphere of "respecting knowledge and talents". Project fragmentation refers to the status that various talents policies in different regions are nearly to be content assimilation. Weak commercialization refers to the phenomenon that current policy support mainly concentrated in research institutes, 
universities and other state-owned levels, while less support for enterprises or multinational companies to attract foreign high-level talent. "value introducing but neglect self-cultivation" means that China overemphasize the induction of overseas talents but ignore the cultivation of local talents.

After the introduction of high-end talents, there are still shortcomings in the scientific research platform construction, performance evaluation, team building and other aspects [49]. It is necessary to combine rigidity management with flexible management [54]. Rigidity management is the traditional hierarchy management system in organizations, while flexible management have advantage in adjustable talent incentive and deployment system [55]. From the partial perspective, considering differential regional development, effects of high-quality talent policies are varied. In some developed region, such as Xia Men, Guang Zhou, although successfully induction some high-quality professionals, but contradiction between Policy supply and market demand imbalances; government policies and individual requirements are not in harmony; personnel policy and organizational needs do not converge etc. [56]. In addition, some less developed region, such as Shandong, Hebei Jiangxi province, their attraction for high-quality talent can't compete with more developed regions, and talents are more intend to outflow. Subsequently these regions' talent administration more emphasizes the efficiently employing rather than personnel training, because efficiently employing is less cost but yield quick returns [57].

Dividing by research subject, high-quality talent management can be sort into two main parts, before-induction and after-induction. Before-induction include the research on the high-quality talent's recruitment and induction. Reference [58] take young talented people who are members of Thousand Talent Program as research subject. Her paper analyzes the flow characteristics, distribution, and structural characteristics of talents by means of curriculum vitae information. Based on the bibliometric, this paper analyzes academic productivity, influence, the structure, and evolution innovation network of scientific research cooperation before and after returnees return home. The results indicate that young talents are main from 30-35 year-old male groups, from the well-known universities research institutions and first-class enterprises in developed countries, mainly in the life sciences, engineering and materials. After the introduction, the overall has strong academic productivity and influence. High-quality professionals' scientific research cooperation networks are scale-free network which have small world-scale characteristics. Also, active in scientific research in various fields, and formed a certain size of the research team. Reference [59] highlight the importance of evaluation based on different criteria. Such as evaluate the program from the selection subject, selection range, selection time, selection process, content and evaluation criteria and other aspects. Furthermore, this comprehensive evaluation must be done in the early stage of talent introduction, policy supply needs to improve the supporting measures, team building and subject construction must be promoted, and the performance evaluation must be practical [60]. Additionally, the evaluation should synergistic combine with economic contract and the psychological contract, as well as combine the talents employment with the overall development strategy [61].

After-induction research include high-quality talent compensation management, performance management, talent ethic, talent culture, talent incentives and training and so forth [62]. High-quality talent's compensation should be competitive and incentive [63]. In the public-fund organizations, such as universities and hospital, institution should establish the government compensation policy, formulate the reasonable salary distribution plan, innovate the "overall salary" management mode, the tenure system and increase the legislative protection of high-level personnel compensation system [60], [64]. Performance management is a key link in talent management. Essentially, based on the empirical research, the performance valuate index should consider the difference in discipline, and combine the unalterable quota with alterable quota [54]. And this performance evaluation can be combined with other incentive methods [65].

In brief, current researches are closer to strategic HRM, include typical human resource components such as hiring, discipline and compensation. But talent management is the last wave of human resource. In most of the organizations such as universities and hospitals, there exist less business and industrial competition, but occur competition for employment and maintenance of talent with high skills [66]. Therefore, the necessity of establishing high efficiency talent management to improve organizational performance is highly felt.

High-quality talent policies are officially initiated from 2008 to cope with the international finance crisis. Both the recruitment program for Thousand Talent and Ten Thousand Talent have implemented no more than ten years. And the effect of the policy is gradually revealed. Better working conditions and preferential treatment are the competitive privilege of these program. But only few articles conduct empirical research on the ongoing impact of the two Programs on certain disciplines or organizations. Even more importantly, evaluation on these series talent programs whether to meet the demand of high-quality talents before their induction are rarely found in the literatures. Current research more focused on the induction of high-quality talent but less on the effective utilization. Hence, high-quality personnel come back to work in China full of sympathetic feelings, but quit from the organizations regretfully. Whereas, China's political regime are different from the other countries, the administration framework in state-owned organizations are also distinct from others. Therefore, distinctive research context will make the research have Chinese characteristic. As mentioned earlier, talent management should not be framed from a narrow perspective, and research should identify and clarify what happen in organization's practice [67]. Further empirical analyze for broader perspective and more balanced theoretical framework for high-quality talent management are expected.

\section{CONCLUSION}

High-quality talent conception is originated from two crucial talent programs in China: The Recruitment Program of 
Global Experts and Special Support Program for National High-quality professionals. These two official programs cover both overseas and domestic prominent professionals. Guided by these programs, each organization have issued their respective talent plan and criteria. However, current research literatures are mainly from Chinese scholars, and research perspective is limited. Reasons as follows: i. inadequate publicity of these new talent programs, academia's interests are focus on the traditional talent flow phenomenon, such as brain drain and Multinational enterprise talent management. ii. Research objects are traditional topics, such as recruitment, compensation, incentives, performance evaluation and comparison. Value talent induction but less on talent utilization. Additionally, high-quality talent programs are mainly applicable to public-sector organizations, which are funded or owned by state. High-quality talents are also preferable to flow into public-sector organizations. Empirical research is needed to further analyze the cause of talent's employment decision and the pulling power of these talent program. Furthermore, these public-sector organizations have a unique characteristic which are different from other countries, the administration principle is "human resources under the Party leadership", this would be an important element in high-quality talent management.

\section{REFERENCES}

[1] D. G. Collings and K. Mellahi, "Strategic talent management: A review and research agenda," Human Resource Management Review, vol. 19, no. 4, pp. 304-313, 2009.

[2] C. Tansley et al., Talent: Strategy, Management, Measurement, CIPD, 2007.

[3] E. E. Lawler III, Talent: Making People Your Competitive Advantage, John Wiley \& Sons, 2010.

[4] M. Thunnissen, P. Boselie, and B. Fruytier, "Talent management and the relevance of context: Towards a pluralistic approach," Human Resource Management Review, vol. 23, no. 4, pp. 326-336, 2013.

[5] D. Farrell and A. J. Grant, "China's looming talent shortage," The McKinsey Quarterly, vol. 4, no. 56, pp. 70-79, 2005.

[6] E., Hartman, E. Feisel, and H. Schober, "Talent management of western MNCs in China: Balancing global integration and local responsiveness," Journal of World Business, vol. 45, no. 2, p. 169-178, 2010.

[7] P. Iles, X. Chuai, and D. Preece, "Talent management and HRM in multinational companies in Beijing: Definitions, differences and drivers," Journal of World Business, vol. 45, no. 2, pp. 179-189, 2010.

[8] T. N. Garavan, "Global talent management in science-based firms: an exploratory investigation of the pharmaceutical industry during the global downturn," The International Journal of Human Resource Management, vol. 23, no. 12, pp. 2428-2449, 2012.

[9] P. Sparrow, E. Farndale, and H. Scullion, "An empirical study of the role of the corporate HR function in global talent management in professional and financial service firms in the global financial crisis," The International Journal of Human Resource Management, vol. 24, no. 9, pp. 1777-1798, 2013.

[10] C. Tansley, S. Kirk, and S. Tietze, "The currency of talent management - A reply to "talent management and the relevance of context: Towards a pluralistic approach," Human Resource Management Review, vol. 23, no. 4, pp. 337-340, 2013.

[11] Farndale, E., H. Scullion, and P. Sparrow, "The role of the corporate HR function in global talent management," Journal of World Business, vol. 45, no. 2, pp. 161-168, 2010.

[12] D. Preece, P. Iles, and R. Jones, "MNE regional head offices and their affiliates: Talent management practices and challenges in the Asia Pacific," The International Journal of Human Resource Management, vol. 24, no. 18, pp. 3457-3477, 2013.

[13] H. Scullion and D. Collings, Global Talent Management, Routledge, 2011.

[14] R. E. Lewis and R. J. Heckman, "Talent management: A critical review," Human Resource Management Review, vol. 16, no. 2, pp. $139-154,2006$
[15] B. D. Smart, Topgrading: How Leading Companies win by Hiring, Coaching, and Keeping the Best People, Penguin, 2005.

[16] E. Michaels, H. Handfield-Jones, and B. Axelrod, The War for Talent, Harvard Business Press, 2001.

[17] J. W. Boudreau and P. M. Ramstad, Beyond HR: The New Science of Human Capital, Harvard Business Press, 2007.

[18] M. A. Huselid, R. W. Beatty, and B. E. Becker, "'A players' or 'A positions'?" Harvard Business Review, 2005, vol. 83, no. 12, pp. 110-117.

[19] G. K. Stahl et al., "Global talent management: How leading multinationals build and sustain their talent pipeline," INSEAD Faculty and Research Working Papers, vol. 24, 2007.

[20] B. E. Becker, M. A. Huselid, and R. W. Beatty, The Differentiated Workforce: Transforming Talent into Strategic Impact, Harvard Business Press, 2009.

[21] W. G. Tymon, S. A. Stumpf, and J. P. Doh, "Exploring talent management in India: The neglected role of intrinsic rewards," Journal of World Business, vol. 45, no. 2, pp. 109-121, 2010.

[22] P.W. Larson and M. T. Richburg, "Overview of leadership coaching," The Talent Management Handbook, p. 307, 2004.

[23] A. Giordano and A. Pagano, "Brazil in the transition towards knowledge economy: between qualification and internationalization of human capital," Transition Studies Review, vol. 20, no. 1, pp. 19-31, 2013.

[24] L. Cerna, "The crisis as an opportunity for change? High-skilled immigration policies across Europe," Journal of Ethnic and Migration Studies, vol. 42, no. 10, pp. 1610-1630, 2016.

[25] Z. Zong, "A study on the policy of introducing overseas high - level talents in local government - a case study of Changzhou city," Journal of Shanghai Jiaotong University, vol. 4: pp. 7-13, 2010.

[26] J. Tiqing, "The high - level talent strategy model and its selection in Shandong province," Modern Management Science, vol. 10, pp. 27-29, 2012.

[27] Q. He and Y. Chen, "Evaluation on the effect of overseas high - level talents' introduction policy - taking the "Thousand Talents Program" as an example," Science \& Technology Progress and Policy, vol. 30, no. 16, pp. 107-112, 2013

[28] B. Li and D. Zou, "Study on the Effect Evaluation and Policy Optimization of 'Hundred Talents Program' of Hubei Overseas High level Talents," Science \& Technology Progress and Policy, vol. 32, no. 9, pp. 32-35, 2015.

[29] F. Yao, The Temptation of the Country: Secret of China 's Highest Level of Talent Program, 2011.

[30] H. Zhu, "Constructing a new model of high - level personnel management in enterprises - taking Chongqing as an example," Chinese Journal of Human Resources Development, vol. 10, pp. 61-64, 2010.

[31] W. Sun, Z. Ren, and Y. Zhang, "An analysis of the present situation of the introduction of overseas high - level talents: A case study of thousand plan," Chinese Science Fund Journal, vol. 30, no. 1, pp. 80-84, 2016

[32] D. Fan, "The Risk of Introducing High - level Talents in Universities Influencing Factors and Suggestions," Journal of Higher Education Research, vol. 6, pp. 39-45, 2014.

[33] N. Dries, F. Van Acker, and M. Verbruggen, "How 'boundaryless' are the careers of high potentials, key experts and average performers?" Journal of Vocational Behavior, vol. 81, no. 2, pp. 271-279, 2012.

[34] K. E. Weick, "Gapping the relevance bridge: Fashions meet fundamentals in management research," British Journal of Management, vol. 12, 2001.

[35] I. Reichlin, "Getting the global view," Chief Executive, vol. 202, pp 44-50, 2004

[36] Z. Han, "Empowerment, relaxation, vigor flow - review of talent work in 2016," China Organization and Personnel, 2017.

[37] G. Brookfield, Global Relocation Trends Survey Report 2013, Brookfield Global Relocation Services, 2013.

[38] P. P. Lasserre et al., "Human resources management in China and the localization challenge," Journal of Asian Business, vol. 13, pp. 85-100, 1997.

[39] K. Leung, "Theorizing about Chinese organizational behavior: the role of cultural and social forces, in Handbook of Chinese organizational behavior: integrating theory, research and practice," Edward Elgar Publishing, Massachusetts. pp. 13-28, 2012.

[40] A. Varma, P. P. Budhwar, and S. Pichler, "Chinese host country nationals' willingness to help expatriates: The role of social categorization," Thunderbird International Business Review, vol. 53, no. 3, pp. 353-364, 2011. 
[41] J. Lauring and J. Selmer, Multicultural organizations: Common language, knowledge sharing and performance," Personnel Review, 2011, vol. 40, no. 3, pp. 324-343.

[42] V. Peltokorpi and L. Clausen," Linguistic and cultural barriers to intercultural communication in foreign subsidiaries," Asian Business \& Management, vol. 10, no. 4, pp. 509-528, 2011.

[43] R. Konopaske and S. Werner, "US managers' willingness to accept a global assignment: do expatriate benefits and assignment length make a difference?" The International Journal of Human Resource Management, vol. 16, no. 7, pp. 1159-1175, 2005.

[44] R. Konopaske, C. Robie, and J. M. Ivancevich, "A preliminary model of spouse influence on managerial global assignment willingness," The International Journal of Human Resource Management, vol. 16, no. 3, pp. 405-426, 2005.

[45] D. Zweig, "Competing for talent: China's strategies to reverse the brain drain," International Labour Review, vol. 145, no. 12, pp. 65-90, 2006.

[46] R. Gui, Study on the Staus Quo of China's returned overseas High-level talents and Analysis of Strategy Research, 2014.

[47] H. Tian et al., "Research on the policy of attracting high - level talents in developed countries and its reference to Tianjin city," Science and Technology Progress and Policy, 2012, vol. 29, no. 20, pp. 142-145.

[48] W. Xu, L. Lan, and H. Zhang, "Study on the evaluation index system of introducing high - level talents in Donghu High-tech Zone," Science \& Technology Progress and Policy, vol. 31, no. 2, pp. 125-128, 2014.

[49] J. Fei et al., "Study on the present situation of overseas high - level talents' introduction and the countermeasures - taking jiangsu province as an example," Science and Technology Management Research, vol. 34, pp. 107-111, 2014.

[50] S. Yanling, "Research on the selection of high-level talents project in China," China Human Resource Development, vol. 9, pp. 82-87, 2016.

[51] F. Gao, J. Cai, and J. Hou, "The introduction and cultivation strategy of high-level talents in colleges and universities," Modern Communication (Journal of Communication University of China), vol. 5, pp. 127-131, 2010.

[52] Z. Dailiang et al., "Status quo, problems and countermeasures of China's high-quality talent policy," Science Research Management, vol. $9,2012$.

[53] Z. C. Zhu et al., "Analysis on the growth and management of high-level innovational young scientific talents in China," Science and Technology Progress and Policy, vol. 28, no. 9, 2011.

[54] L. Xiuchao, "Study on the Management Path of High - level Talents in Colleges and Universities," Chinese Journal of Adult Education, vol. 20, 2013.

[55] C. Fang, "The application of flexible management mode in human resource management," China Collective Economy, vol. 36, 2011.

[56] J. Liu et al., "Discussion on Incentive mechanism of high - level talents in university under the view of academic," The Party Building and Ideological Education in Schools, vol. 22, no. 85-86, 2012.
[57] H. Y. Jia et al., "Research on soft environment of sustainable development of high level talents - taking Hebei province as an example," China Talent, vol. 13, no. 24-25, 2010.

[58] F. Yang and Y. Liu, "Analysis on the characteristics and quality of young high-level talents," Journal of Scientific Research Management, vol. 1, 2016.

[59] Y. Sun, "Research on the selection of hig -level talents project in china china human resource development," vol. 9, pp. 82-87, 2016.

[60] F. Zhao et al., "Current situation and consideration of high-level talent salary management in public hospital," Jiangsu Health Management, vol. 26, no. 3, pp. 4-6, 2015.

[61] X. W. Liu, "A study on the strategy of high-level talent introduction in local colleges and universities in Shaanxi," Journal of Baoji University of Arts and Sciences (Social Science Edition), vol. 3, 2016.

[62] J. Wenli, Study on the Ethical Problems of High-level Talent Management, 2013.

[63] Y. Mou, "High-quality talent compensation management research. China talent," vol. 3, pp. 30-31, 2013.

[64] H. R. Li et al., "International comparison of high-level talents salary system in colleges and universities," Modern Education Management, vol. 7, pp. 124-128, 2012.

[65] Z. Fuli, "Research on performance evaluation and salary incentive of high-level talents in China medical university," Xi'an University of Technology, 2010.

[66] Z. Bidmeshki et al., "Comparing the present and ideal situation of succession planning and talent management in higher education," Quarterly Journal of Research and Planning in Higher Education, vol. 20, vol. 2, pp. 51-72, 2014.

[67] M. Thunnissen et al., "Talent management," Employee Relations, vol. 38 , no. 1 , pp. 57-72, 2016.

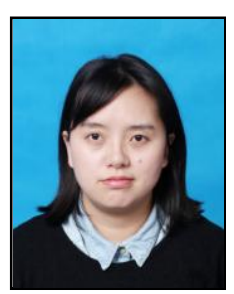

Dan zhou born in China in June 1981. She got te B.Ec and B.A degree from Central China Normal University, Wuhan, China in June 1999; MSc degree in management from Zhongnan University of Economics and Law, Wuhan, China in June 2003. She is a doctoral candidate in labor economics in Zhongnan University of Economics and Law, Wuhan, China. She is also a postgraduate research associate in Queen Mary University of London, UK. Her major field of study is international human resource management and labor economics.

She used to work in Wuhan Economy College as a junior lecturer. Her current research interests are international talent management and organization change.

Ms. Zhou gets the reward of Prominent Teacher in the College and won full scholarship twice in Zhongnan University of Economics and Law, Wuhan, China. She gets state fund for her visit in UK. 